\title{
Aportaciones sobre la composición de los esmaltes, barnices y pastas de la porcelana del Buen Retiro. Nuevos datos documentales.
}

\author{
C. MAÑUECO \\ Museo Arqueológico Nacional 28006 Madrid
}

\begin{abstract}
Se publica por por primera vez la transcripción íntegra del documento de Manuel de Agreda, ultimo director de la Manufactura de Porcelana del Buen Retiro sobre la fabricación de la porcelana y colores. Se incluyen las composiciones, materias primas y proceso de fabricación de tres pastas y cerca de cuarenta esmaltes, barnices y pigmentos. La publicación se enmarca dentro del renovado interés existente sobre los estudios integrados: artísticos y técnicos, de la historia de la cerámica.
\end{abstract}

Palabras clave. porcelana, esmaltes, barnices, pigmentos, pastas, Buen Retiro, historia cerámica

Contributions on Buen Retiro Porcelain's compositions: enamels, glazes and pastes. New documental dates

The transpcripton of Manuel de Agreda's manupscrit, tje last Buen Retiro Porcelain's Manufacture director is, for first time published. Data on composition and raw materials for more than forty pastes, enamels, glazes, pigmentes is included. This work is insert in the renewed interest on the pluridisciplinary approach, artistic and technical to the Buen Retiro ceramic history studies

Key words. Porcelain, enamels, glazes, pigements, pastes, Buen Retiro, ceramic history.

\section{Nota del Editor}

Los editores han decidido publicar este trabajo solo en su versión en español, dadas las dificultades para obtener una adecuada traducción al inglés de un texto redactado originalmente en 1808, con numerosos términos topononímicos o técnicos sin traducción correcta

\section{Editor's note}

The editors have decided to publish only in the spanish versión, taking into account the dificculties to obtain a accurate translation of the numerous words related to toponymys and specific technical words

La localización de nuevos datos documentales referentes a la Manufactura de Porcelana del Buen Retiro ha permitido profundizar en el conocimiento de su historia, y estudiar su evolución y desarrollo durante los años que estuvo en funcionamiento (1760-1808).

Sin embargo, hasta el momento han sido escasas las noticias encontradas que tuvieran relación con la composición de la pasta, del barniz, o de los colores utilizados para decorar las piezas. Esta circunstancia revaloriza aún más la importancia histórica de un documento manuscrito conservado en el Archivo del Instituto Valencia de Don Juan, que dimos a conocer recientemente (1).

El documento lo forman diecisiete hojas de tamaño cuartilla, escritas a tinta por ambas caras y grapadas. En la hoja que hace de portadafigurael siguiente título: "Retiro 1808. Procedimientos de la fabricación de la porcelana y colores de Dn, Manuel de Agreda".

El valor del manuscrito por sí mismo, así como el interés que ofrece su contenido nos ha decidido a publicarlo íntegramente, aunque, como se indicará más adelante, los datos contenidos en la primera parte del mismo habían sido dados a conocer hace casi un siglo. El texto se ha transcrito literalmente, si bien para que su manejo resultara más sencillo se ha dividido el documento en cuatro Apartados, numerados del I al IV. Con el fin de facilitar el acceso a referencias puntuales del texto se ha dado un número a cada una de las fórmulas en él contenidas. Las adiciones al documento van en negritas.

\section{TRANSCRIPCIÓN DEL DOCUMENTO:}

Copia de los apuntes que sobre la composición de Porcelana y colores para pintarla dejó de su mano Dn Manuel de Agreda último Director de porcelana y colores del Retiro en 1808.

Los debo a la generosa bondad de su hijo Dn Domingo de Agreda catedrático jubilado de quimica gral de Valladolid y antiguo Director de la fab. de porcelana de Nast en Paris. Apartado I 


\section{Fabricacion de porcelana}

Las materias que componen una verdadera porcelana son dos, la una refractaria o infusible y la otra fusible.

La primera es la arcilla o alumina mas o menos cargada de materias siliceas, lo que hace variar la cantidad de la materia fusible que se ha de mezclar, segun la arcilla es mas ó menos pura.

A falta de una arcilla que tenga las cualidades que se requieren se sirve del Quarzo (1), la Roca cornea, o cualquiera otra materia silicea, con tal que al fuego resulte blanca; que es una de las qualidades que han de tener todas las materias que entran en la composición de la Porcelana.

La segunda que es la fusible es el Feldespato (2) esta es una piedra inferior en dureza al Quarzo; se halla mas ó menos sólido, lo que le hace variar de fusibilidad, cuanto mas solido es mas fusible, se funde al fuego y forma la cubierta ó barniz de la Porcelana

Se encuentra menos sólido y más descompuesto (3) y este ultimo es preferible para la mezcla de la pasta por salir esta mas ductil para el trabajo, o elaboración de las piezas, y por mayor facilidad de molerlo.

(1) En Galapagar 4 leguas de Madrid, hay canteras enormes de quarzo excelente

(2) Feldespato solido se halla tambien en abundancia en dicho Galapagar

(3) Media legua antes de llegar a Colmenar viejo, 5 legs. de Madrid, en el sitio llamado el Majuelo de Laso se muestra Feldespato descompuesto excelente.

Razon de la composicion de la Porcelana y colores que usaba en la Real Fabrica de la China del Buen Retiro, en el año 1808 hallandome Director de la fabricacion de porcelana y colores en dicha Rl. Fabrica

1)

\section{Pasta de Porcelana}

4 partes

2 y media

\section{Quarzo de Galapagar}

Feldespato descompuesto del Majuelo de Laso, media leg ${ }^{\mathrm{a}}$ antes de Colmenar viejo.

2 Arcilla magnesiana de una arroyada al norte de la huerta Zabala, pasado la fuente del Caño gordo

\section{Barniz o cubierta}

24 partes de Feldespato de Galapagar

4 partes Porcelana cocida

En La Coruña se encuentra abundancia de una arcilla excelente, resultada de la descomposición del Granito, que es lo que los franceses llaman Kaolin, por darle este nombre los chinos. Se hicieron traer unas treinta @ (arrobas) para ensayarla; salio muy buena porcelana del modo siguiente.

2)

\section{Pasta}

48 partes

Arcilla de La Coruña (1) decantada o colada por un tamiz muy fino, y despues de seca, se echaban en dichas 48 partes.

7 partes Su Quarzo o materia silicia que resultaba

3 y media

del decantado o colado

Carbonato de cal, este ensayo se hizo con el carbonato de la Mancha al cual lo traen para venderlo a los pintores y economizar el albayalde, pero es muy comun en todas partes.

(1) Esta arcilla tiene la particularidad de tener en combinación algunas materias que equivalen al feldespato, por lo que en las operaciones se varia en un todo de cuando las materias son puras; y asi hasta el barniz que le corresponde es en un todo distinto como en la pagina siguiente se verá.

\section{Barniz o cubierta para la pasta anterior}

\begin{tabular}{|c|c|}
\hline 12 partes & Arcilla de la Coruña decantada \\
\hline 16 & su Quarzo que sale de la decantación \\
\hline 6 & Carbonato de cal \\
\hline & Feldespato de Galapagar \\
\hline
\end{tabular}

Nota. En toda la provincia de Galicia, y tambien en Asturias, se hallan en abundancia Feldespatos y de todas las demas materias a proposito para la Porcelana

3)

\section{Barniz bueno}

$\begin{array}{ll}28 \text { partes } & \begin{array}{l}\text { Feldepato semidescompuesto cargado } \\ \text { de Mica de Valdemorillo }\end{array} \\ 6 & \text { Carbonato de cal } \\ 4 & \text { Feldepato de Galapagar }\end{array}$

Una de las grandes dificultades que se encuentra en la fabricación de Porcelana son; primera, el graduar la proporción de las mezclas de modo que a veces si se carga la dosis de la materia fusible, las piezas se tuercen en el fuego; segunda, si se carga de la materia refractaria, el barniz grietea; por esta causa hice grandes ensayos en los ultimos dias antes de la destruccion de dicha Fábrica por las tropas francesas; conociendo que si llegaba a lograr que la pasta hecha con mayor cantidad de materia refractaria no grietase, era una ventaja muy grande por no torcerse ninguna pieza en el fuego.

Despues de repetidos ensayos de barnices para este efecto hice en los últimos dias uno que en pequeño tuvo el resultado deseado, pero al irlo a ensayar en grande escala sucedio el trastorno por los franceses, y es del modo siguiente:

14 partes
3

5)

\section{Barniz ensayado en pequeño}

Feldepato de Galapagar

Quarzo

Piedra magnesiana de Vallecas que sale a la falda del cerro de Almodovar, de la que hace hornillos

\section{Tierra para cajas}

La tierra para cajas debe ser muy refractaria, por lo que en muchos años no se ha conocido otra que pudiera servir sino la de Zamora. Pero ultimamente se ha hallado otra equivalente en Miraflores de la Sierra en el termino llamado el Prado de las Animas de la que tambien es menester hacer uso para la construcción de los hornos. 


\section{Apartado II}

Dorado y colores hechos en dicha Rl Fabrica cuyo resultado era lo mismo que los de Paris.

6)

\section{Dorado}

Disuelvese el oro, hecho planchitas muy delgadas, en el acido nitro muriatico, por nombre comun agua Regia, que no es otra cosa mas que agua fuerte con sal amoniaco, y se disuelve a calor suave de Arena ó del sol. Disuelto que sea se filtra por un papel de seda. (Se advierte que todas las vasijas y embudos y demas instrumentos deben ser de vidrio, cristal o porcelana).

Después por separado se toma sulfato de hierro, por otro nombre caparrosa, y disuelto en agua caliente se filtra.

Estando esto asi prevenido se toma la disolución de oro y se vierte en una vasija de vidrio, donde haya un azumbre ó más de agua caliente, y en este estado, se vierte sobre la disolución de oro, la disolución del sulfato de hierro; y al instante empieza el oro a precipitarse en un color oscuro. Estando bien posado, se decanta el licor, que sobrenada. Despues se va echando agua caliente sobre el precipitado y decantandolo se sigue esta operacion hasta que no ha quedado nada de acidez. Después de bien lavado, el precipitado se saca y despues de seco se mezcla con el fundente.

7)

$$
\begin{array}{ll}
6 \text { partes } & \text { Oxido de Bismuth precipitado por el agua. } \\
1 & \text { Borax calcinado }
\end{array}
$$

Todo bien mezclado y puesto al fuego hasta aglutinarse

La cantidad de fundente que se le mezcla es, a cada octavo de precipitado de oro, que son 72 gramos, dos gramos de dicho fundente, y moliendolo en la losa con aceite graso y aguarras; mezclando primero el aceite graso, que el aguarras, pues de lo contrario se convierte en hojas; y bien molido se deja secar sobre la losa y despues se recoge con un cuchillo y se guarda así para su uso.

Para dorar sobre la porcelana, se toma un poco de dicho oro y se deslie en un planito de cristal con un poco de aceite graso, aguarrás y aceite de espliego; y con el pincel se hacen los adornos que se quieran sobre las piezas, advirtiendo que el obrador en donde se dore ha de estar templado para que el oro corra.

Despues de dorada la pieza, y si se necesita ademas poner algunos colores, puestos que sean se meten las piezas doradas y pintadas en la mufla, y dandola el fuego necesario para que los colores y el oro se fijen en las piezas, se quita el fuego, y dejandola enfriar se sacan las piezas, los colores brillantes y hermosos, y el oro de un color mate. Despues lo que ha de ser bruñido, se bruñe con un bruñidor de agata y de piedra sanguina, frotándolo también con un poco de carbonato de cal de la Mancha, llamado tambien blanco de España.

\section{Apartado III}

Operaciones para las purpuras y carmines, para los que se emplea el oro.

Disuelto a calor suave de Arena

9)

$\begin{array}{ll}3 \text { onzas } & \text { Acido nítrico } \\ 6 \text { onzas } & \text { Agua filtrada } \\ 36 \text { gramos } & \text { Sal de cocina }\end{array}$

Puesto esto en un bocalito de vidrio o cristal, se toma estaño de Indias y pasado por cilindro de modo que quede hecho unas cintas muy delgadas, las que se van cortando unos pedacitos con tigeras, y hechos estos como unos barquitos, se van echando sobre el licor quedandose sobre él, y no se echa otro pedazito hasta que el anterior este disuelto, que de este modo sale mas limpio.

Se necesita 2 ó 3 dias para saturarse de estaño, esto se conoce cuando se disuelven los pedazos con dificultad, y entonces la disolucion tiene un color parecido a la del oro.

Nota: esta disolución se hace en un parage fresco porque sino sale turbia.

10)

\section{Purpura llamada de baño}

Despues de filtrada la disolucion de oro, se vierte en un bocal grande de vidrio donde haya gran cantidad de agua hirviendo, y despues se va echando la disolución de estaño, hasta que se vea que empieza a precipitar en un color de vino oscuro.

En habiendo precipitado todo, se decanta el agua clara y el residuo o precipitado se pone en un filtro y se le va echando agua caliente hasta que pase el agua sin nada de acidez.

Estando asi labado se deja orear el filtro, y sin acabar de secarse se echa sobre la losa y se le mezcla el fundente carmin que necesita y un poco de cristal de roca (1)

Para chatiron se guarda el precipitado seco y sin fundente, y sirve para perfilar las hojas y dar el verde encima.

(1) Esta operación de mezclar el fundente carmín antes de secarse el precipitado, es para que no se oscurezca, como sucederia despues de seco. Siempre se le suele mezclar menos de lo que necesita, y cuando se va a gastar se hace una porción, yendole echando fundente y metiéndola unos casquitos de porcelana con unas pinceladas en la muflita de ensayos, y cuando se ve que corre no necesita mas.

11)

\section{Fundente carmin}

$\begin{array}{ll}100 \text { partes } & \text { Borax fundido } \\ 60 & \text { Quarzo o cristal de roca } \\ 20 & \text { Minio o litarge }\end{array}$

Para el color Rosa se mezcla a dicho fundente carmin, un poco de muriate de plata y otro poco mas de cristal de roca.

12)

1 parte
1 parte
1 parte

1 parte

\section{Color Rojo n ${ }^{\circ}$ 1. Maon}

Oxido de Zinc

Oxido de Bismuth

Oxido de hierro, el cual se prepara disolviendo el hierro en el acido nitrico (aguafuerte) separando el acido a fuego lento y lavandolo bien despues. de fundente gris 
Todo esto mezclado se pone en una cazuela o crisol, dandole primero un baño de arena o quarzo molido, para que no se pegue se pone al fuego hasta aglutinarse.

Se muele despues dos partes de lo dicho con una del mismo fundente gris y queda asi para usarlo.

13)

4 partes
1

14)

1 parte

3

15)

1 y cuarta parte Oxido de hierro del sulfato calcinado tres veces, habiendolo lavado bien la primera vez; y cada una de las tres veces que se funda, se muele en la losa con agua.

3 partes Fundente gris

16)

1

3

17)

1 parte

3 y cuarta

18)

1 y cuarta
3 y cuarto

19)

18 partes

6 "

$2 "$

1 parte

1 "

20)

18 partes

4

2

1

21)

\section{Rojo $N^{\circ} 2$ y 3}

fundente gris

Oxido de hierro que queda despues de haber precipitado el oro; y precipitado dicho sulfato por la potasa, y después calcinado hasta ponerse rojo.

\section{Rojo $\mathbf{n}^{\circ} 4$}

Oxido de hierro, por el sulfato calcinado y lavado

Fundente gris

\section{Rojo $n^{\circ} 5$}

\section{Rojo $n^{\circ} 6$ o violado}

Vena de hierro calcinada fuerte

Fundente gris

Rojo $\mathbf{n}^{\circ} 7$

Sombra calcinada, se conoce en el comercio por tierra sombra de Venecia

Fundente gris

\section{Otro}

Sombra idem. sin calcinar

Fundente gris

\section{Amarillo $n^{0} 1$}

Litarge o minio

Quarzo o arena blanca

calcinacion de plomo y estaño; esta se hace calcinando 2 partes de plomo y 1 de estaño barrilla o sosa purificada Antimonio diaforetico

\section{Amarillo $n^{0} 2$}

Litarge o minio

Quarzo o arena blanca

Oxido de antimonio por el nitro a diaforetico

Oxido de hierro por el sulfato calcinado

o labado

\section{Amarillo n 3}

Antimonio diaforetico

$\begin{array}{lll}1 \text { y media " } & \text { Oxido de hierro } \\ 6 & " & \text { fundente roncalla } \\ 4 & " & \text { Borax }\end{array}$

Estos amarillos se funden en un crisol, y estando bien fundidos se guardan para su uso.

22)

1 parte

23)

\section{Amarillo que se puede arreglar con los carmines}

Antimonio diaforetico

calcinacion de plomo y estaño, esto mezclado y molido al agua sobre la losa, y despues calcinado hasta ponerse amarillo, y estando así se mezcla con otro tanto de fundente de carmin y queda hecho.

\section{Fundente Maon que se puso en el horno de embizcochado, muy bueno.}

$\begin{array}{lll}2 & \text { y media partes } & \text { fundente gris } \\ \text { Un cuarto } & \text { Borax fundido } \\ 1 & ״ & \text { Zinc } \\ 1 & \text { “ } & \text { Bismuth }\end{array}$

De esto cuatro partes, y una de oxido de hierro del sulfato precipitado por la potasa y media parte de Borax.

24)

\section{Operaciones para un verde}

18 partes de
6
10

1 y media

Minio

Arena blanca o quarzo

Oxido de cobre, por el acido nitrico precipitado por la potasa, y calcinado hasta ponerse negro.

Todo junto se funde en un crisol y desde el fuego se vierte en agua.

Despues se mezcla una parte de esto con 4 del amarillo ${ }^{\circ} 1$ ( ver receta ), se muele sobre la losa y en polvo se guarda para el uso.

25)

\section{Azul de Rey}

$\begin{array}{ll}8 \text { partes } & \text { Oxido de cobalto } \\ 8 & \text { Quarzo o arena blanca } \\ 12 & \text { Potasa pura y blanca }\end{array}$

Puesto en un crisol despues de bien molido, se funde a fuego de porcelana, y pulverizado se guarda para el uso.

26)

\section{Azules}

$\begin{array}{cl}16 \text { partes } & \text { Nitro } \\ 8 & \text { Quarzo o arena blanca }\end{array}$

Fundese y el vidrio que resulta se mezcla 9 partes de dicho vidrio con 18 de arseniato de cobalto (antes que seque en el filtro) perfectamente molido; se seca en una taza a un calor lento; se vuelve a moler otra vez en seco, y se reververa a todo fuego de mufla; y de esto mezclado con fundente gris hasta estar en su punto, pues se va probando en la mufleta de ensayos. 
Meclando este azul con su fundente gris y poniendolo en un crisol en el horno de porcelana, resulta el mejor azul que se puede hallar; advirtiendo que se debe poner en el horno, lo mas distante de los hogares.

\section{Otro azul.}

Lo mismo que el anterior solo que a 9 partes del vidrio de nitro y quarzo, se ponen 30 del arseniato de cobalto, o 40 segun lo mas o menos humedo.

28)

\section{Negro}

$\begin{array}{ll}9 \text { partes } & \text { Oxido de colbalto } \\ 9 & \text { Manganeso } \\ 4 & \text { Azul subido } \\ 2 & \text { Carmín subido } \\ 32 & \text { fundente gris }\end{array}$

29)

\section{Otro negro}

$\begin{array}{ll}1 \text { parte } & \text { Manganesa de Alemania } \\ 1 & \text { Azul preparado para pintor } \\ 2 & \text { fundente gris }\end{array}$

30)

\section{Tinta de China}

$$
\begin{array}{ll}
4 \text { partes } & \text { fundente gris } \\
10 \text { y media } & \text { Manganesa de Alemania }
\end{array}
$$

La manganesa para este color se prepara tomando solo los cristales brillantes y estos puestos en aguafuerte se lava. Es menester advertir que cuando empieza a precipitarse se decanta a otro vaso para separarlo de las partes terrosas y groseras que se precipitan las primeras. Tomando la manganesa en este estado se calcina hasta rojo; se mezcla con su fundente y se guarda para su uso.

\section{Apartado IV}

Varios colores que no he experimentado; solo los he apuntado de unos ensayos hechos en Paris.

\section{Verde amarillento.}

$\begin{array}{ll}1 \text { y media parte } & \text { Antimonio diaforetico } \\ 1 \text { y media } & \text { Oxido de hierro rojo } \\ 2 & \text { Oxido de cobre húmedo del Nitrato por la } \\ & \text { potasa } \\ 4 & \text { Borax fundido } \\ 6 & \text { Minio } \\ 2 & \text { Quarzo (todo fundido) } \\ & \text { Rojo }\end{array}$

1 de Mina de hierro calcinada con 4 de fundente del sulfato de hierro amarillo por el licor siliceo

El licor silicio se hace tomando 4 partes de Potasa y 1 de Quarzo; se funden en un crisol, y disuelto en agua se hecha en la disolución del sulfato de hierro; el hierro y la silice caen precipitados al fondo y hacen unos colores muy buenos.

\section{Color rosa}

El precipitado de Casio estando humedo y molido con su fundente; y despues de seco, poner todo el fundente que se necesita con el muriato de plata hasta rosa; y despues poner 4/10 de oxido blanco de estaño por el acido nitrico y el fundente que corresponda a este.

Todo junto fundido a aglutinarse y remobido bien.

34)

$\begin{array}{ll}30 \text { partes } & \text { Feldespato } \\ 9 & \text { Granates }\end{array}$

Para mezclar:

$\begin{array}{cl}30 \text { partes } & \text { Feldespato } \\ 9 & \text { Manganeso } \\ 1 & \text { Quarzo }\end{array}$

Para mezclar:

$\begin{array}{cl}30 \text { partes } & \text { Feldespato } \\ 9 & \text { residuo de cobalto } \\ 1 & \text { Quarzo }\end{array}$

35)

\section{Otro color}

$\begin{array}{cl}10 \text { partes } & \text { Cobre calcinado en escamas } \\ 10 & \text { Zinc } \\ 3 & \text { Borax }\end{array}$

\section{Disolucion y precipitado de Plata}

Se disuelve la Plata en el acido nitrico; en la disolución se vierte una solucion de sal de cocina y se hace un precipitado blanco.

De este precipitado se sirve para la Porcelana.

37)

\section{Nitrato de Plata}

Se disuelve la Plata en el acido nitrico y despues evaporandolo hasta sequedad.

Para hacer el tornasol ó nacar sobre la porcelana, se mezcla con el color un poco de nitrato de plata, y se pone en la mufla a la fumigacion, que se hace con los materiales animales como son la lana, el cuero, y produce dichos fondos.

\section{Disolución y precipitado de Platina}

La platina se disuelve en el acido nitro muriatico (agua regia) y se precipita por una disolucion de muriate de amoniaco; se saca el precipitado rojo y cristalino que se forma y se reduce en polvo fino; se hace colorear ligeramente en un vasija de vidrio y el muriate de amoniaco que esta precipitado con la platina se sublima, y el metal queda al fondo bajo la foma de un polvo gris ligero.

39)

\section{Platina}

Despues de preparada en polvo como queda dicho, se mezcla a cada onza de polvo un octavo de fundente del mismo modo y el mismo que para el oro.

Se debe poner poca esencia grasa para emplearlo y se bruñirá con el bruñidor de agata solamente.

El fuego debe ser mas fuerte que para el oro.

Se debe emplear muy cargado de platina. 
Se da una mano de aceite graso que es aceite cocido con oxido de Bismuth y se echa encima polvo de oro; se cuece y despues de pone otra vez aceite solo y se le da otra mao de polvo de oro.

\section{1)}

\section{Cobalto}

El mejor cobalto es el que viene de Suecia aunque contiene algunas materias hetereogeneas y arsenico. Para obtenerlo puro, se hace calcinar fuertemente en un crisol en la parte superior del horno y se tiene durante se cuecen las piezas. Preparado asi se disuelve en el acido nitrico (agua fuerte) el cual se precipita por la potasa caustica para obtener un precipitado de color de rosa, que a poco y mucho fuego resulta un azul excelente, teniendo el fundente que necesita como queda dicho en la composicion de los colores.

\section{Comentario al documento:}

Los apuntes que dejó de su mano Manuel de Agreda, junto con un informe redactado por el director de la Manufactura madrileña, Bartolomé Sureda, en 1808, constituyen la fuente de datos más completa que hasta el momento poseemos acerca de los procedimientos de fabricación de la porcelana del Buen Retiro.

Estas dos fuentes documentales fueron consultadas y utilizadas en su día por Pérez Villamil, para redactar su libro sobre Porcelana del Buen Retiro, que vió la luz en 1904. De ambas extrajo dicho autor la mayor parte de los datos referentes a las técnicas de fabricación de la porcelana empleadas en la época de Sureda (1803-1808), que figuran en el capitulo VI de su obra (págs. 47-52). De los apuntes de Manuel de Agreda, Pérez Villamil recogió en su libro la parte del documento que nosotros hemos denominado Apartado I. Sin embargo, dicho autor no se sirvió, ni dió a conocer noticia alguna de la existencia, ni del contenido de los Apartados II a IV de dichos apuntes, que han permanecido inéditos hasta este momento.

Tal y como aparece en el propio documento, el contenido del manuscrito de Manuel de Agreda pasó a poder del Conde de Valencia de Don Juan por mediación de su hijo, Domingo de Agreda.

Manuel de Agreda, riojano de nacimiento, era hermano del escultor Esteban de Agreda, Jefe del Obrador de Escultura del Buen Retiro (1797-1808). Con anterioridad a su llegada a Madrid, al parecer, había regentado una Fábrica de Loza en la localidad de Haro (Logroño). Desconocemos en qué fecha comenzó a trabajar en la Fábrica madrileña, si bien aparece citado en los documentos desde el año 1799, en relación con la localización o el aprovisionamiento de gredas a la Manufactura de porcelana.

Pudiera ser que se incorporara a Buen Retiro poco tiempo después de haber sido nombrado director Bartolomé Sureda (1803), puesto que el año 1805 le fue encomendada la responsabilidad de "la porcelana en blanco". Ese mismo año, fue nombrado suplente para cubrir las ausencias del director "de manera provisional hasta que demostrara su capacidad". En 1807 le fue asignada la "Dirección del Obrador de Porcelana en Blanco y el Laboratorio de Colores" con la misma categoría y responsabilidad que tenían los directores de los Obradores de Escultura y Pintura (2).

El director Bartolomé Sureda, en la demanda de separación del cargo de director, que redactó el 8 de noviembre de 1808, comenta que durante su mandato había estado instruyendo a personas para que pudieran hacerse cargo de cada uno de los ramos de la Fábrica, .."particularmente Dn Manuel de Agreda que posee todos los conocimientos de la fabricacion de la porcelana en estado blanco y composición de todos los colores y oro para decorarla" (3). Sureda abandona Buen Retiro definitivamente en diciembre de dicho año. En esa fecha, Agreda debio de hacerse cargo oficialmente de la dirección de Fábrica, cuyos hornos llevaban seis meses sin cocer porcelana.

Estos datos constatan el grado de preparación que tenía Manuel de Agreda. Ahora bien, fue Agreda el autor de estas fórmulas, de alguna de ellas, o únicamente las recopiló para que no se perdieran ?. Pudiera resultar válida cualquiera de estas hipótesis, si bien por nuestra parte, tras haber manejado un número elevado de documentos sobre el Buen Retiro, seguimos considerando a Bartolome Sureda no sólo el autor de la transformación que se operó en la Fábrica, sino también el descubridor en Madrid de la pasta de porcelana dura.

\section{BIBLIOGRAFIA}

(1) Mañueco Santurtun, C.- "La Real Fábrica de Porcelana del Buen Retiro a través de sus documentos (1760-1808)". En: Manufactura del Buen Retiro 17601808 , p. 20

(2) id., p. 110

(3) Instituto de Valencia de Don Juan. Archivo. Fábrica del Buen Retiro. "Excmo. Sr: Dirijo...los...Estados ... de Ventura (Bartolome) Sureda. 2 de marzo 1808. 8 de noviembre de 1808 (varios docs.)

La importancia de las investigaciones que se han venido efectuando en los últimos años, sobre la historia y la técnica de la Real Fábrica del Buen Retiro, ha sido reconocida por la C.A.M, que financia actualmente, entre otros, el proyecto de Investigación "Las Cerámicas del Buen Retiro" (Proy: 06/0104/1999). En este nuevo proyecto se incluyen investigadores de los siguientes centros: Instituto de Cerámica y Vidrio e Instituto de Ciencias de la Construcción del CSIC; Instituto Tecnológico Geominero de España, Museo Municipal de Madrid, Escuela Madrileña de Cerámica de la Moncloa, Dirección General del Patrimonio C.A.M y Museo Arqueológico Nacional. 